\title{
Successful thoracic endovascular aortic repair for post-coarctoplasty aneurysm
}

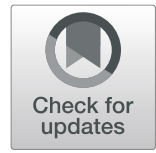

Sedigheh Saedi ${ }^{1 *}$, Maryam Aliramezany ${ }^{2}$, Jamal Moosavi ${ }^{1}$ and Tahereh Saedi ${ }^{1}$

\begin{abstract}
Background: Aortic coarctation is currently treated by both surgical and transcatheter methods. Patients can present with late complication of prior surgical repair including recoarctation and aneurysm formation. There are limited reports on safety and efficacy of thoracic endovascular aortic repair methods (TEVAR) in post-coarctation repair patients.

Case presentation: We report an adult patient with aortic aneurysm formation following surgical coarctoplasty successfully treated with transcatheter TEVAR method obviating the need for open heart surgery.

Conclusion: Endovascular repair of aneurysms in post-coarctoplasty patients is a promising method and should be considered in those with suitable anatomy based on prior imaging.
\end{abstract}

Keywords: Aorta, Coarctation, Aneurysm, Endovascular repair, Case report

\section{Background}

Aortic coarctation refers to the congenitally stenotic aorta, more commonly found near the ligamentum arteriosum and adjacent to the left subclavian artery [1]. Coarctation of the aorta occurs in one out of 2500 live births with a male to female ratio of 2:1 and is now treated either surgically or percutaneously. Coarctation repair can improve the survival and prognosis if the intervention is performed in time [2]. However, there are well-known entities in the follow-up of these patients including recoarctation and formation of true or false aneurysms. Here we report a patient with postoperative complication treated successfully by catheter intervention.

\section{Case presentation}

A 25-year-old female with history of surgical repair of coarctation in infancy and percutaneous device closure of a mid-muscular ventricular septal defect (VSD) at age eighteen presented to our adult congenital clinic for routine follow-up. She stated that she was asymptomatic and had

\footnotetext{
* Correspondence: sedsaedi@gmail.com

${ }^{1}$ Rajaei Cardiovascular Medical and Research Center, Iran University of Medical Sciences, Vali-asr Ave, adjacent to Mellat Park, Tehran, Iran Full list of author information is available at the end of the article
}

normal functional capacity. Physical examination findings were within normal limits. Chest X-ray showed normal heart size and an abnormal bulging in the upper left heart border suggesting aneurysmal dilation of thoracic aorta (Fig. 1). Cardiac magnetic resonance (CMR) imaging was performed for surveillance of the coarctation repair site and revealed formation of a large aneurysm in distal part of the aortic arch and proximal part of descending thoracic aorta measuring an anteroposterior diameter of 50 $\mathrm{mm}$ that also involved the origin of the left subclavian artery (Fig. 2). Given the inherent risk of complications or rupture as the aneurysm had formed at site of previous surgical repair, we decided to have a lower threshold for intervention in this young patient. The patient refused any surgical options; therefore, percutaneous repair of the aneurysm by thoracic endovascular aortic repair (TEVAR) method was planned.

\section{Intervention}

Aortography was performed via femoral route, and injections were done using a radiopaque marker pigtail to get accurate measurements. Aortic angiography confirmed CMR findings (Fig. 3). 


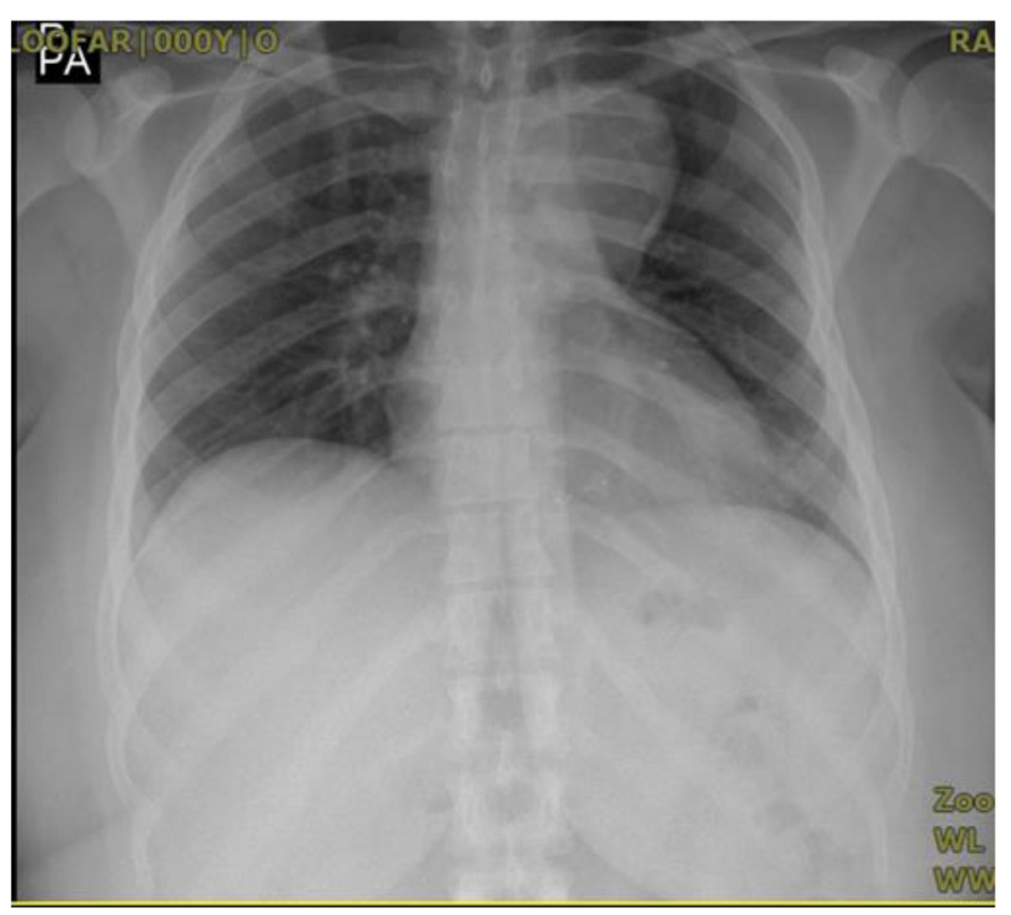

Fig. 1 CXR depicting aneurysmal dilation of the aorta

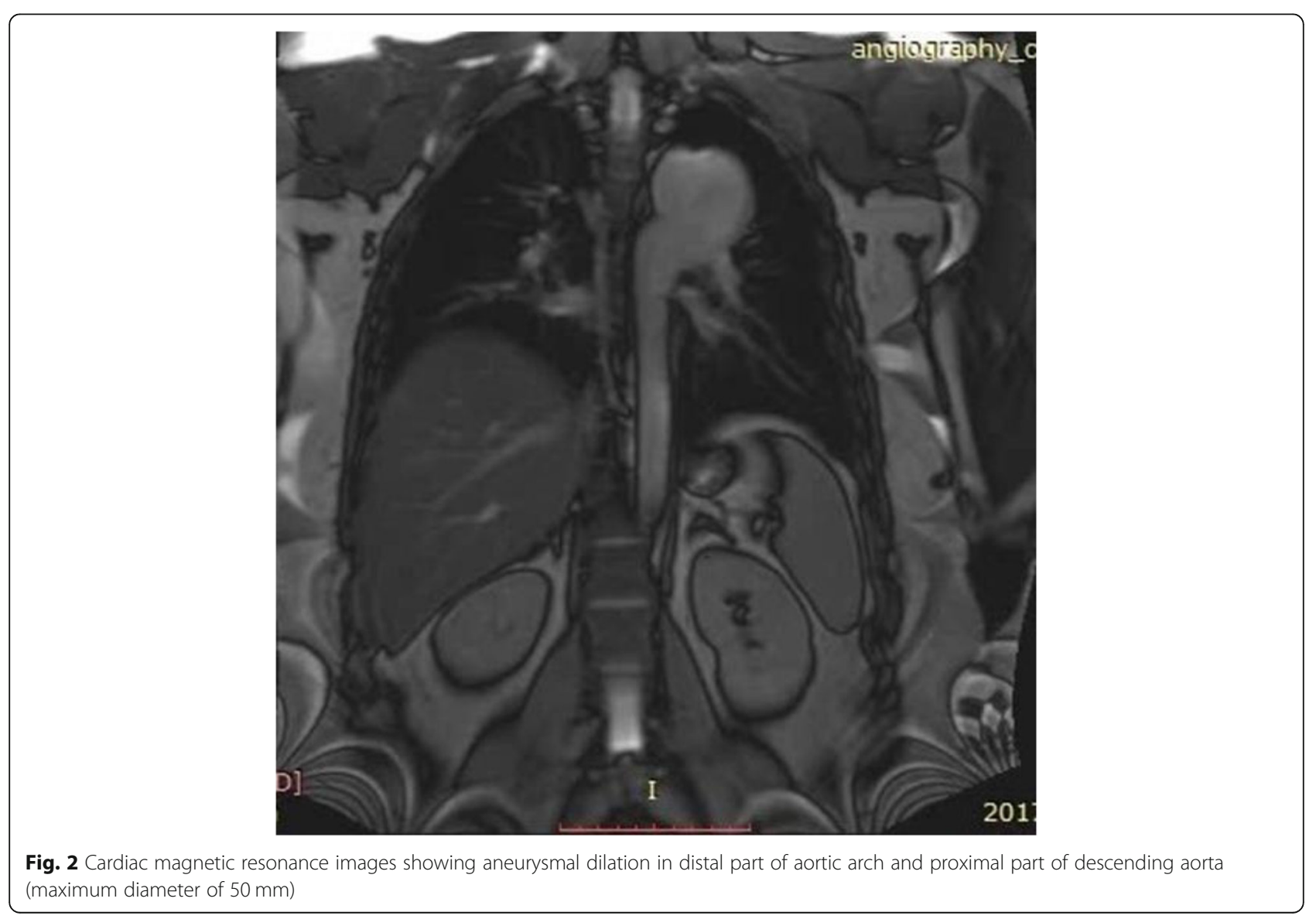




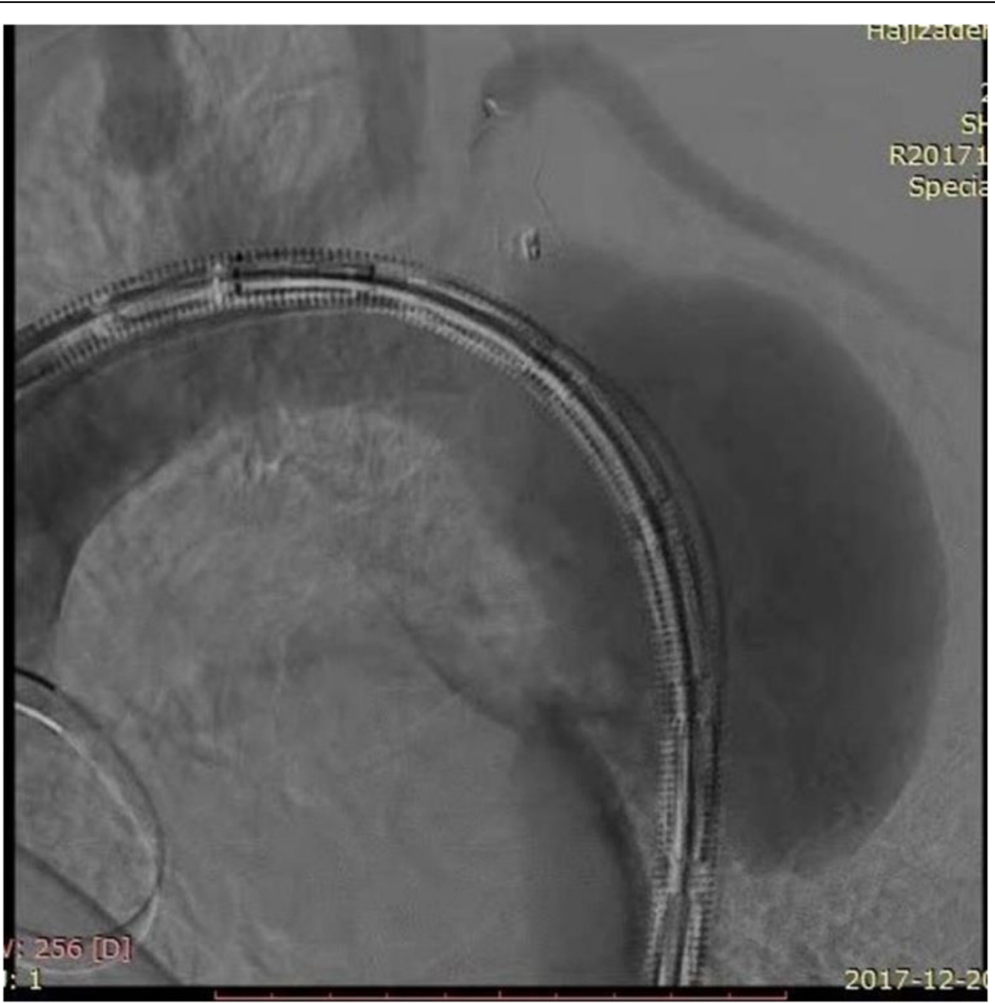

Fig. 3 Aortic angiography showing the aortic aneurysm

Initially, the left subclavian artery ostium was occluded using a Occlutech ${ }^{\circ}$ PDA occluder $8 \times 10 \mathrm{~mm}$ to eliminate the risk of endoleaks (Fig. 4).Then a $24 \times 24 \times 120$ mm stent graft (Zenith Alpha ${ }^{\mathrm{mu}}$ Thoracic Endovascular Stent Graft ,Cook Medical) was deployed just after left carotid artery with successful results and without complication (Fig. 5). Stent length was selected based on pre-procedural CT angiography, and the stent was costume made to be $20 \%$ longer than the CT-measured diseased portion of the aorta of about $93 \mathrm{~mm}$.
Follow-up CT angiography showed complete exclusion of the aneurysm with no complications (Fig. 6). At 1year follow-up post-intervention, the patient was doing well with no reported worrisome issues.

\section{Discussion}

Repair of aortic coarctation has traditionally been based on surgical methods although catheter interventions are progressively improving [3]. Different surgical approaches including resection with end-to-end anastomosis, direct

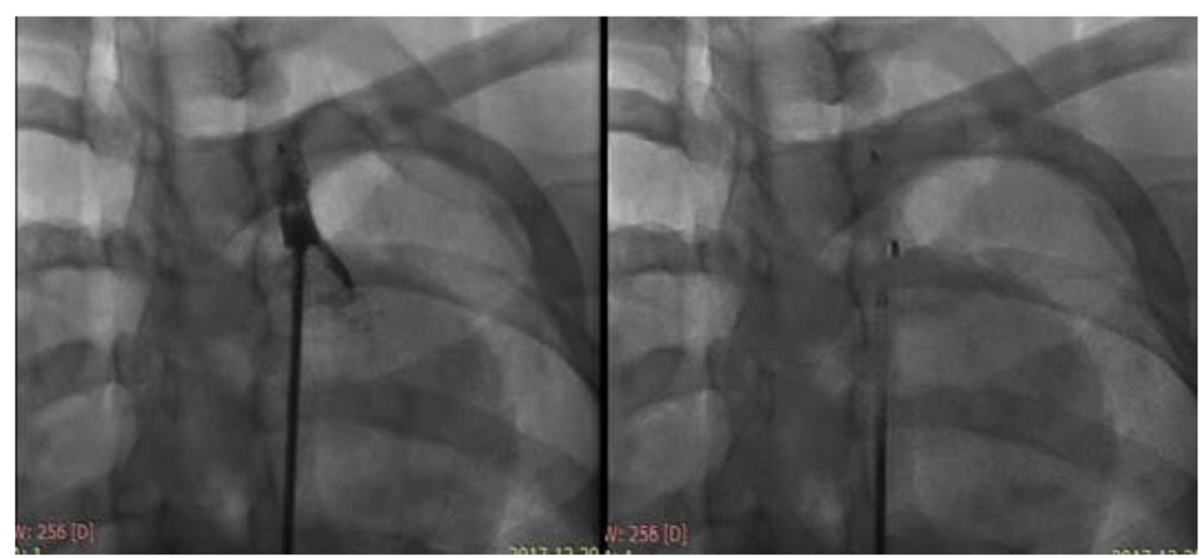

Fig. 4 Obstruction of the subclavian artery with PDA device 


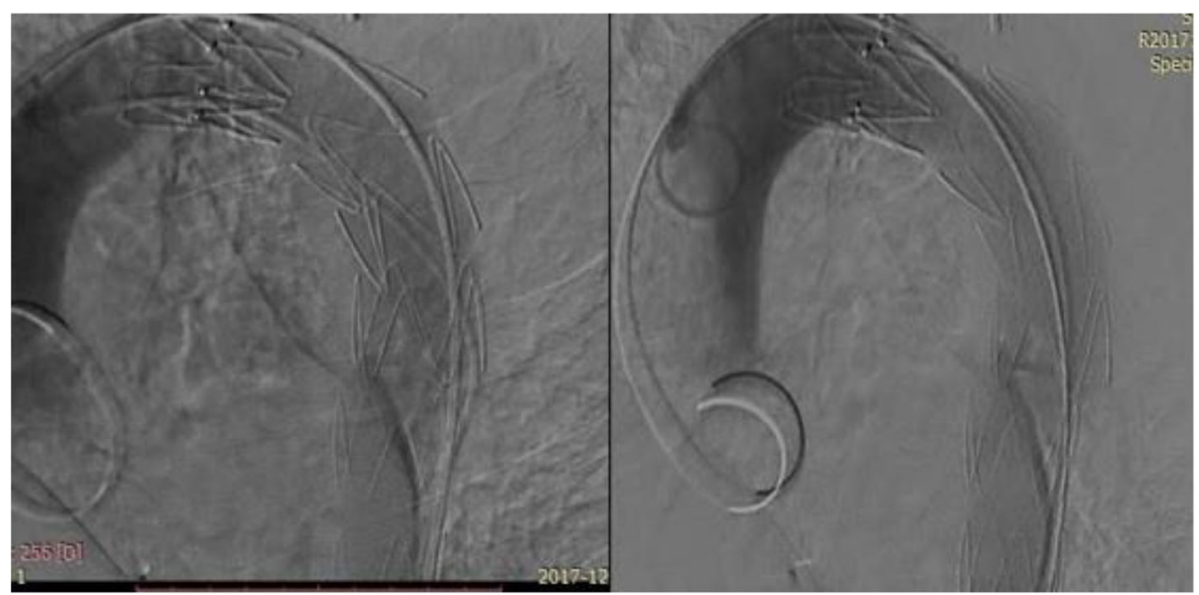

Fig. 5 Stent graft deployed just after left carotid artery

aortoplasty using transverse suture repair, patch-graft aortoplasty, subclavian flap aortoplasty, and resection with end-to-end conduit interposition are used for surgical correction. In spite of successful repair of coarctation, postsurgical patients are still at risk of long-term complications including recurrence of the aortic coarctation and true or false aortic aneurysm formation with risk of dissection, rupture, or fistulization to adjacent structures. Although aneurysm formation at the site of repair is relatively more common after patch graft aortoplasty it is seen following other approaches including bypass grafting, end-to-end anastomosis, or subclavian flap aortoplasty and even after transcatheter interventions [4]. The aneurysm usually develops as a result of a more flexible vessel wall compared to the patch, long-lasting hypertension, or extreme resections of the aortic rim [3]. Hence, to protect patients against complicated aneurysms, we need to identify them early by regular follow-up imaging. Relatively high mortality and morbidity is seen with the repeat surgical repair of postsurgical complications, and the best management strategy has yet to be established .Reoperation following previous patch-graft aortoplasty is reported to have a $14 \%$ mortality rate and substantial morbidity, including paraplegia and bleeding complications [5]. In addition, patients often prefer minimally invasive options.

Although endovascular stent grafting has been approached cautiously in the treatment of such young patients, newer stent graft designs offer better conformability and durability, and endovascular stent grafting could be considered as a safe option for treatment of these patients. Advantages of stent grafts include the fact that they could cover the total length of the diseased aorta. However, long-term efficacy and freedom of reintervention remain to be investigated.

Yazar et al. in their series of 13 patients with TEVAR for treatment of late complications after aortic coarctation reported cases suffering mortality and morbidity [6]. Lala et al. reported 21 adult patients with primary coarctation or post repair complications, four of whom had pseudoaneurysm and were treated with TEVAR, with acceptable results and no mortality. However, there were cases with reported endoleaks and patients requiring reinterventions during their 8 months of follow-up [7]. Erben et al. also reported 11 patients with postoperative aneurysm/pseudoaneurysm in their case series, all of whom were treated with stent grafts. Four patients needed concomitant left

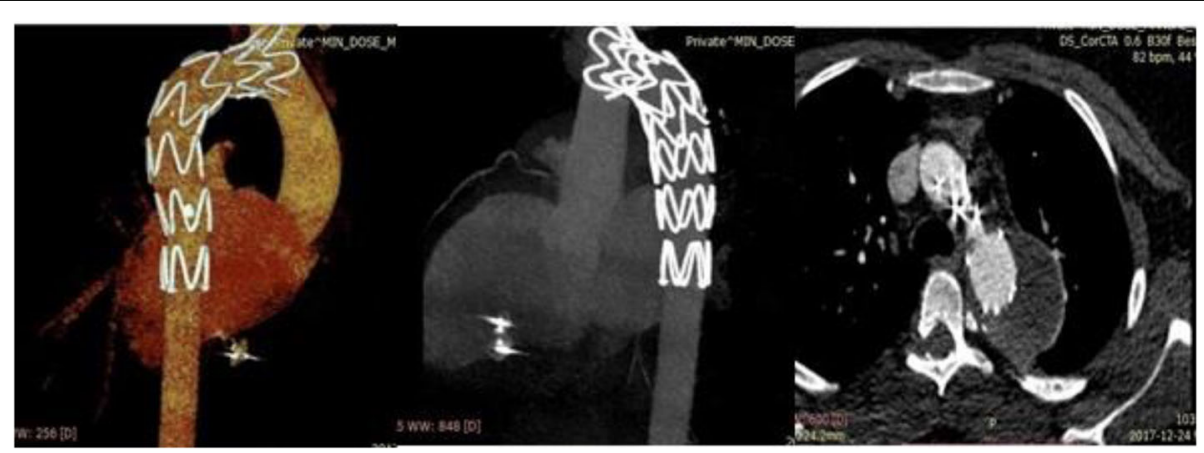

Fig. 6 Follow-up CT angiography showing complete exclusion of the aneurysm 
carotid to left subclavian artery bypass and two a right carotid to left carotid to left subclavian artery bypass [8]. Our patient had the left subclavian artery prophylactically occluded to avoid the risk of endoleak. As the patient did not develop upper extremity claudication, there was no need for left subclavian bypass grafting.

\section{Conclusion}

The present case highlights the importance of considering percutaneous methods of aneurysm repair in patients who are optimal candidates based on prior imaging, over the routine open surgical alternatives and thereby averting the risks associated with repeat surgical procedures. Large and multi-center trials with long-term follow-up focusing on postsurgical patients are needed to further clarify the role and potential shortcomings of the endovascular stent grafts in the management of these patients.

\section{Abbreviations}

VSD: Ventricular septal defect; PDA: Patent ducus arteriousus

\section{Acknowledgements}

None

\section{Authors' contributions}

Case concept and design: SS, JM. Acquisition of data: MA, TS. Drafting of manuscript: SS, MA. Revision: SS, JM, TS. All authors have read and approved the manuscript.

\section{Funding}

None

\section{Availability of data and materials}

N/A

\section{Ethics approval and consent to participate}

Patient consent was obtained and ethics committee of RHC approved of the study.

\section{Consent for publication}

Written informed consent to publish this information was obtained from study participants.

\section{Competing interests}

None

\section{Author details}

${ }^{1}$ Rajaei Cardiovascular Medical and Research Center, Iran University of Medical Sciences, Vali-asr Ave, adjacent to Mellat Park, Tehran, Iran.

${ }^{2}$ Afzalipour Hospital, Kerman University of Medical Sciences, Kerman, Iran.

Received: 15 November 2019 Accepted: 20 March 2020

Published online: 30 March 2020

\section{References}

1. Warnes CA, Williams RG, Bashore TM, Child JS, Connolly HM, Dearani JA, del Nido P, Fasules JW, Graham TP, Hijazi ZM, Hunt SA. ACC/AHA 2008 guidelines for the management of adults with congenital heart disease: a report of the American College of Cardiology/American Heart Association Task Force on practice guidelines (writing committee to develop guidelines on the management of adults with congenital heart disease) developed in collaboration with the American Society of Echocardiography (ASE), Heart Rhythm Society, International Society for Adult Congenital Heart Disease, Society for Cardiovascular Angiography and Interventions(SCAI), and ....
Journal of the American College of Cardiology (JACC). 2008 Dec 2;52(23): e143-263.

2. Brown ML, Burkhart HM, Connolly HM, Dearani JA, Cetta F, Li Z, Oliver WC, Warnes CA, Schaff HV (2013) Coarctation of the aorta: lifelong surveillance is mandatory following surgical repair. Journal of the American College of Cardiology. 62(11):1020-1025

3. Preventza O, Livesay JJ, Cooley DA, Krajcer Z, Cheong BY, Coselli JS (2013) Coarctation-associated aneurysms: a localized disease or diffuse aortopathy. Ann Thorac Surg. 95(6):1961-1967

4. Oliver JM, Gallego P, Gonzalez A, Aroca A, Bret M, Mesa JM (2004) Risk factors for aortic complications in adults with coarctation of the aorta. Journal of the American College of Cardiology. 44(8):1641-1647

5. Von Kodolitsch Y, Aydin MA, Koschyk DH, Loose R, Schalwat I, Karck M, Cremer J, Haverich A, Berger J, Meinertz T, Nienaber CA (2002) Predictors of aneurysmal formation after surgical correction of aortic coarctation. Journal of the American College of Cardiology. 39(4):617-624

6. Yazar O, Budts W, Maleux G, Houthoofd S, Daenens K, Fourneau I (2011) Thoracic endovascular aortic repair for treatment of late complications after aortic coarctation repair. Ann Vasc Surg. 25(8):1005-1011. https://doi.org/10. 1016/j.avsg.2011.05.031

7. Lala S, Scali ST, Feezor RJ, Chandrekashar S, Giles KA, Fatima J, Berceli SA, Back MR, Huber TS, Beaver TM, Beck AW. Outcomes of thoracic endovascular aortic repair in adult coarctation patients. J Vasc Surg. 2018 Feb;67(2):369-381.e2. doi: https://doi.org/10.1016/j.jvs.2017.06.103. Epub 2017 Sep 22.

8. Erben $Y$, Oderich GS, Verhagen HJM, Witsenburg M, van den Hoven AT, Debus ES, Kölbel T, Arko FR 3rd, Torsello GB, Torsello GF, Lawrence PF, Harlander-Locke MP, Bacharach JM, Jordan WD Jr, Eskandari MK, Hagler DJ (2019 Mar) Multicenter experience with endovascular treatment of aortic coarctation in adults. J Vasc Surg 69(3):671-679.e1. https://doi.org/10.1016/j. jvs.2018.06.209

\section{Publisher's Note}

Springer Nature remains neutral with regard to jurisdictional claims in published maps and institutional affiliations.

\section{Submit your manuscript to a SpringerOpen ${ }^{\circ}$ journal and benefit from:}

- Convenient online submission

- Rigorous peer review

- Open access: articles freely available online

- High visibility within the field

- Retaining the copyright to your article

Submit your next manuscript at $\boldsymbol{\nabla}$ springeropen.com 